\title{
Synthesis, spectroscopic, magnetic properties and superoxide dismutase (SOD) activity of copper (II) complexes with N-(2- hydroxy ethyl)-2-iminodiacetic acid and polypyridine ligands
}

\author{
R. N. Patel ${ }^{\mathrm{a}}$, S.P. Rawat ${ }^{\mathrm{a}}$ and M. Choudhary ${ }^{\mathrm{b}}$. \\ ${ }^{a}$ Department of Chemistry, A.P.S. University, Rewa (M.P.) 486003 India. \\ ${ }^{b}$ Department of Chemistry, National Institute of Technology Patna,(Bihar) 800005 India.
}

\begin{abstract}
Three new ternary copper(II) complexes formulated as [Cu(HIda)(bipy)] 1; [Cu(HIda)(phen)] 2; $[\mathrm{Cu}(\mathrm{HIda})(\mathrm{dmp})] \mathrm{3}$; where HIda $=N$-(2-hydroxyethyl)-2- iminodiacetic acid $;$ bipy $=2,2$ '- bipyridine; phen = 1,10- phenanthroline; dmp = 2,9-dimethyl 1,10-phenanthroline, have been synthesized and characterized by partial elemental analysis, FAB-mass $(\mathrm{m} / \mathrm{z}), E P R, U V$-visible and $C V$ measurements. The magnetic and spectroscopic data of all these complexes 1-3 indicate distorted octahedral geometry. The EPR spectra of these complexes in frozen DMSO solutions showed a single at $g$ ca. 2. The trend in $g$-value $\left(g_{\|}>g_{\perp}>2.0023\right)$ suggests that the unpaired electron on copper (II) has $d_{x} 2_{-y} 2$ character. The SOD activities of the complexes have been investigated. Antibacterial and antifungal activity of these complexes were also measured and discussed.
\end{abstract}

Keywords: Copper (II) complexes; EPR spectra; SOD activity, antibacterial and antifungal activity.

\section{Introduction}

Ternary complexes formed between metal ions and two different types of bioligands, namely heteroaromatic nitrogen bases and Schiff bases, may be considered as models for substrate metal ion-enzyme interactions and other metal ion mediated biochemical interactions. Among those compounds, copper (II) complexes are known to play a significant role either in naturally occurring biological systems or as pharmacological agents ${ }^{1-3}$. Copper complexes containing polypyridine ligands (bipy/phen/dmp) and their derivatives are of great interest since they exhibit numerous biological activities such as antitumor ${ }^{4}$, anticandida $^{5}$, antimicrobacterial ${ }^{6}$, and antimicrobial ${ }^{7,8}$, activities etc. Oberley and Buettner ${ }^{9}$ have reported that cancer cells had less superoxide dismutase (SOD) activity than normal cells. Superoxide ion is toxic to cells; a defense mechanism must have been initiated by nature. All organisms, which use dioxygen and many that have to survive an oxygenated environment, contain at least one SOD. Superoxide dismutase (SOD) which can destroy the superoxide very rapidly, is nature's agent for protection of the organism from this radical burden. In fact native SOD enzymes have been shown in many studies to exhibit protection in animal models of inflammatory diseases ${ }^{10}$. In a variety of scenarios, therapeutic dosage of additional SOD enzyme has shown promise, but from a number of viewpoints synthetic metal complexes offer considerable promise as SOD catalysts for pharmaceutical applications. These SODs disproportionate the $\mathrm{O}_{2}{ }^{-}$radical to molecular oxygen and hydrogen peroxide ${ }^{11}$. All SODs employ the two steps ping-pong mechanism shown in Eqs. (1) and (2).

$$
\begin{array}{lll}
\mathrm{O}_{2}^{-}+\mathrm{Cu}^{(\mathrm{II})} & \longrightarrow & \mathrm{O}_{2}+\left[\mathrm{Cu}^{\mathrm{I}}\right] \\
\mathrm{O}_{2}^{-}+\left[\mathrm{Cu}^{\mathrm{I}}\right]+2 \mathrm{H}^{+} & \longrightarrow & \mathrm{H}_{2} \mathrm{O}_{2}+\left[\mathrm{Cu}^{\text {II }}\right]
\end{array}
$$

As an extension of our previous work ${ }^{12,13}$, herein we now report three copper complexes namely [Cu(HIda)(bipy)] 1; [Cu(HIda)(phen)] 2; [Cu(HIda)(dmp)] 3. N-(2-hydroxy ethyl)-2- iminodiacetic acid (HIda) behaves as tetradentate $\left(\mathrm{O}_{3} \mathrm{~N}\right.$ donor) ligand. These complexes were characterized by various physic-chemical techniques. The SOD activities of the complexes have also been investigated.

Experimental (Materials and Methods)

Copper (II) chloride dihydrate was purchased from S.d. fine chemicals, India. All other chemicals used were commercially available and used without further purification. FAB mass spectra were recorded on a JEOL SX $102 / \mathrm{DA} 6000$ mass spectrometer using xenon $(6 \mathrm{kV}, 10 \mathrm{~mA})$ as the FAB gas. The accelerating voltage was $10 \mathrm{kV}$ and the spectra were recorded at room temperature (RT) with m-nitrobenzoyl alcohol as the matrix. Magnetic susceptibility measurements were made on a Gouy balance using a mercury (II) tetrathiocynatocobaltate(II) as calibrating agent $\left(x_{\mathrm{g}}=16.44 \times 10^{-6}\right.$ c.g.s. units $) . \mathrm{UV}$-Vis spectra were recorded at $25^{\circ} \mathrm{C}$ on a Shimadzu UV-Vis recording spectrophotometer UV-1601 in quartz cells. IR spectra were recorded in $\mathrm{KBr}$ medium on a PerkinElmer 783 spectrophotometer. X-band EPR spectra were recorded with a Varian E-line Century Series Spectrometer equipped with a dual cavity and operating at X-band $(\sim 9.4 \mathrm{GHz})$ with $100 \mathrm{kHz}$ modulation frequency at room temperature and at $77 \mathrm{~K}$. TCNE was used as field marker. The frozen solution at $77 \mathrm{~K}$ used for EPR spectra were in $3 \times 10^{-3} \mathrm{M}$ of DMSO solution. The EPR parameters for copper (II) complexes were 
determined accurately using simulation program ${ }^{14}$.Cyclic voltammetry studies were carried out with a BAS-100 Epsilon electrochemical analyzer having an electrochemical cell with a three-electrode system. $\mathrm{Ag} / \mathrm{AgCl}$ was used as a reference electrode, glassy carbon as working electrode and platinum wire as an auxiliary electrode. The in vitro SOD activity was measured using alkaline DMSO as a source of superoxide radical $\left(\mathrm{O}_{2}{ }^{-}\right)$and nitroblue

tetrazolium chloride (NBT) as $\mathrm{O}_{2}^{-}$scavenger ${ }^{15}{ }^{16}$. In general, $400 \mu 1$ sample to be assayed was added to a solution containing $2.1 \mathrm{ml}$ of $0.2 \mathrm{M}$ potasium phosphate buffer $(\mathrm{pH} 8.6)$ and $1 \mathrm{ml}$ of $56 \mu \mathrm{M}$ of alkaline DMSO solution was added while string. The absorbance was then monitered at $540 \mathrm{~nm}$ against a sample prepared under similar condition except $\mathrm{NaOH}$ was absent in DMSO. The in vitro antimicrobial (antibacterial) activities of these complexes were tested using paper disc diffusion method. ${ }^{17,}{ }^{18}$ the chosen strains were $\mathrm{G}(+)$ Staphylococcus and Escherichia coli. The liquid medium containing the bacterial subcultures was autoclaved for $20 \mathrm{~min}$ at $121^{\circ} \mathrm{C}$ and at $15 \mathrm{lb}$ pressure before inoculation. The bacteria were then cultured for $24 \mathrm{~h}$ at $36^{\circ} \mathrm{C}$ in an incubator. The antifungal activity of the compounds have been evaluated against Aspergillus sp. and Pencillium sp. by the Radial Growth Method ${ }^{19,20}$ using czapek's agar medium. The compounds were directly with the medium in 5,10,15 and $20 \mathrm{mM}$ concentrations.

Synthesis of $[\mathrm{Cu}(\mathrm{HIda})($ bipy) $] \mathbf{1} ;[\mathrm{Cu}(\mathrm{HIda})($ phen $)] \mathbf{2}$ and $[\mathrm{Cu}(\mathrm{HIda})(\mathrm{dmp})] \mathbf{3}$

All the present complexes were prepared in a general method. To an aqueous methanolic solution (15 $\mathrm{ml} 1: 3 \mathrm{v} / \mathrm{v}$ ) of copper (II) chloride dihydrate $(1 \mathrm{mmol}, 0.170 \mathrm{~g}$ ), was added to HIda ( $1 \mathrm{mmol}, 0.2 \mathrm{~g})$. The reaction mixture was stirred for $2 h$. A methanolic solution of bipy (1 mmol $0.156 \mathrm{~g})$, phen $(1 \mathrm{mmol}, 0.198 \mathrm{~g})$ and dmp (1 mmol, $0.208 \mathrm{~g}$ ) respectively was reacted under stirring for $0.5 \mathrm{~h}$ at $25^{\circ} \mathrm{C}$. The resulting blue solution was filtered to remove undissolved solids and collected by filtration and washed with methanol. These were dried in air at RT and stored in a $\mathrm{CaCl}_{2}$ desiccator. Yield 70-85\%. Anal. Calc. for $\mathrm{C}_{15} \mathrm{H}_{15} \mathrm{CuN}_{3} \mathrm{O}_{5} \mathbf{1} ; \mathrm{C}, 42.27 ; \mathrm{H}, 3.93 ; \mathrm{N}$, $11.03(\%)$. Found; C 42.22; H, 3.90; N, 11.00(\%). FAB-mass (m/z) calc.: 380.73; Found: 380. Anal. Calc. for $\mathrm{C}_{17} \mathrm{H}_{15} \mathrm{CuN}_{3} \mathrm{O}_{5}$ 2. C, 46.25; H, 3.54; N, 9.39(\%). Found; C 46.20; H, 3.49; N, 9.35(\%). FAB-mass (m/z) calc. 422.76. Found: 422. Analc calc. $\mathrm{C}_{19} \mathrm{H}_{19} \mathrm{CuN}_{3} \mathrm{O}_{5}$ 3. C, 52.67; H, 4.38; N, 9.70(\%). Found; C, 52.65; H, 4.36; N, 9.68(\%). FAB-mass (m/z) calc. 432.81. Found: 432.

\section{Synthesis and characterization}

\section{Results and discussion}

Analytical data of the complexes show that N'-(2-hydroxyethyl)-2- iminodiacetic acid reacts with metal salts in 1:1 molar ratio to give complexes of general composition (scheme1). The complexes are insoluble in water, cold ethanol, benzene, carbon tetrachloride, chloroform and diethyl ether but are fairly soluble in hot ethanol, dimethyl form amide (DMF) and DMSO. All the complexes decompose between 184 and $290^{\circ} \mathrm{C}$. Very low values of molar conductance $\left(2.52-7.34 \Omega^{-1} \mathrm{~cm}^{2} \mathrm{~mol}^{-1}\right)$ of $10^{-3} \mathrm{M}$ solutions of the complexes in DMSO at room temperature indicate that they are non-electrolytes ${ }^{21}$. The present copper (II) complexes are paramagnetic in solid state at room temperature as expected from $\mathrm{d}^{9}$ electronic configuration of $\mathrm{Cu}$ (II) ion. The observed magnetic moments $\left(\mu_{\text {eff }}\right)$ of the copper (II) complexes are 1.77, 1.80, 1.82 B.M., respectively. Be more specific about the other reported copper (II) complexes ${ }^{22-24}$ and are consistent with spin only magnetic moment of 1.732 B.M. foran $S=1 / 2$. 


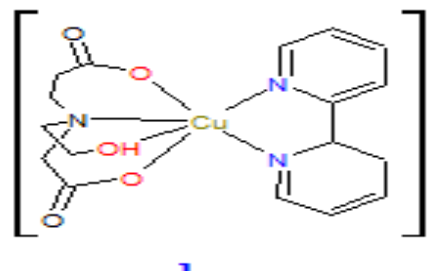

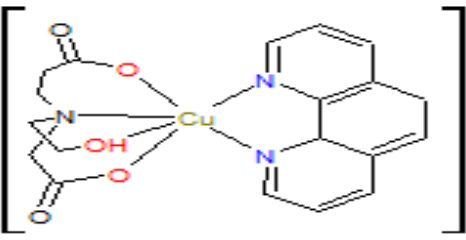
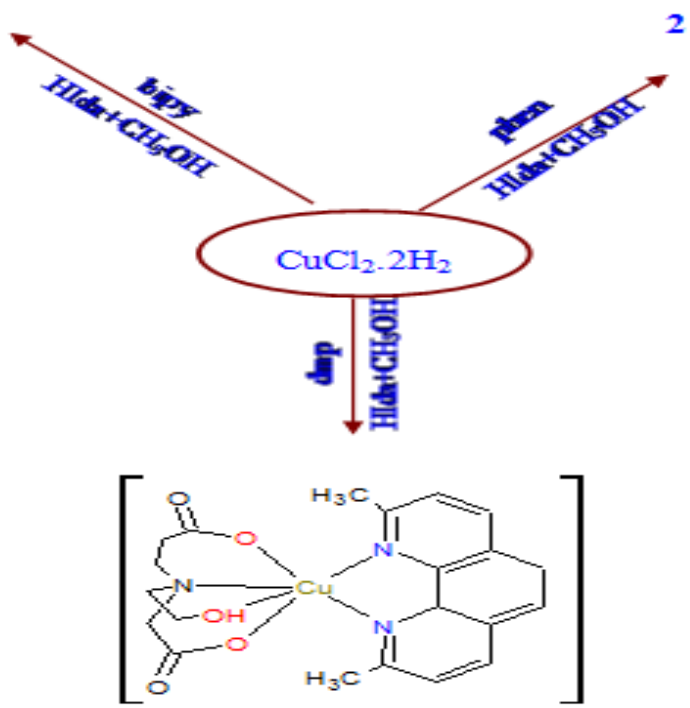

Scheme-2 Synthesis of copper (II) complexes

\section{Electron paramagnetic resonance}

The EPR spectra of polycrystalline samples at $298 \mathrm{~K}$ and in solution at $77 \mathrm{~K}$ were recorded in the Xband region. Some representative spectra are shown in Fig. 1 and 2 and EPR parameters are presented in Table 1. EPR spectra of 1-3 are slightly orthorhombic. Complex $\mathbf{3}$ exhibits a well- resolved hyperfine structure in the $\mathrm{g}_{\mathrm{z}}$ component. Complex 2 exhibit isotropic spectra with $\mathrm{g}_{\mathrm{iso}}=2.127$. The three complexes do not show the $\Delta \mathrm{Ms}=$ \pm 2 signal, indicating absence of copper (II) dimers at $77 \mathrm{~K}$. The frozen solution spectra of the three complexes are axial with $\mathrm{g}_{\|}>\mathrm{g}_{\perp}>2.0$, suggesting the presence of $\mathrm{a} \mathrm{d}_{\mathrm{x}} 2$-y 2 ground state ${ }^{25,26}$. The geometrical parameter $\mathrm{G}$, which is a measure of the exchange interaction between the copper centers in a polycrystalline solid has been calculated ${ }^{27}$, by using the relation. $\mathrm{G}=\left(\mathrm{g}_{\|}-2.0023\right) /\left(\mathrm{g}_{\perp}-2.0023\right)$ for axial spectra and for rhombic spectra $\mathrm{G}=$ $\left(\mathrm{g}_{3}-2.0023\right) /\left(\mathrm{g}_{\perp}-2.0023\right)$ and $\mathrm{g}_{\perp}=\left(\mathrm{g}_{1}+\mathrm{g}_{2}\right) / 2$. According to hathway ${ }^{28,29}$, If $\mathrm{G}>4$ exchange interaction is negligible and if it is $\mathrm{G}<4$ considerable exchange interaction is indicated in the solid complex. These complexes with $\mathrm{g}_{\|}>\mathrm{g}_{\perp}>2.0023$ and $\mathrm{G}$ values less than 4.0 are consistent with a $\mathrm{d}_{\mathrm{x}} 2-\mathrm{y} 2$ ground state. The ratio $\mathrm{g}_{\|} / \mathrm{A}_{\|}$is a sensitive index showing distortion from planarity for the copper site. The values of $\mathrm{A}_{\|} / \mathrm{g}_{\|}$(Table 1 ) for three complexes are very close to that of $\mathrm{Cu}-\mathrm{ZnSOD}^{30}$ which was a $\mathrm{g}_{\|} / \mathrm{A}_{\|} 162 \mathrm{~cm}^{-1}$. Pierre et al. ${ }^{31}$ have synthesized one best $\mathrm{Cu}-\mathrm{ZnSOD}$ model so for having a $\mathrm{g}_{\|} / \mathrm{A}_{\|}$values of $145 \mathrm{~cm}^{-1}$. The EPR parameters and d-d transition energies were uses to evaluated the bonding parameter $\alpha^{2}, \beta^{2}$ and $\gamma^{2}$ which may be regarded as a measure of the covalence of the in-plane $\sigma$ bonding and the in-plane- $\pi$ and out-of-plane $\pi$ bonding, respectively. The in-plane $\sigma$ bonding parameter $\alpha^{2}$ was calculated by using the expression ${ }^{32}$ :

$\alpha^{2}=\left(\mathrm{A}_{\|} / 0.036\right)+\left(\mathrm{g}_{\|}-2.0023\right)+3 / 7\left(\mathrm{~g}_{\perp}-2.0023\right)+0.04$.

The orbital reduction factors $\mathrm{K}_{\|}$and $\mathrm{K}_{\perp}$ were estimated from the expression ${ }^{33}$ :

$\mathrm{K}_{\|}^{2}=\left(\mathrm{g}_{\|}-2.0023\right) \mathrm{E}_{\mathrm{d}-\mathrm{d}} / 8 \lambda^{\circ}, \mathrm{K}_{\perp}^{2}=\left(\mathrm{g}_{\|}-2.0023\right) \mathrm{Ed}-\mathrm{d} / 2 \lambda^{\circ}$

Where $K_{\|}=\alpha^{2} \beta^{2}, K_{\perp}=\alpha^{2} \beta^{2}$ and $\lambda^{0}$ represents the one electron spin - orbit coupling constant for the free ion, equal to $-828 \mathrm{~cm}^{-1}$. Significant information about the nature of bonding in the copper (II) complexes can be derived from the magnitude of $\mathrm{k}_{\|}$and $\mathrm{k}_{\perp}$. In case of pure $\sigma$ bonding $\mathrm{k}_{\|} \approx \mathrm{k}_{\perp} \approx 0.77$ whereas $\mathrm{k}_{\|}<\mathrm{k}_{\perp}$ implies considerable in-plane bonding, while for out-of-plane bonding $\mathrm{k}_{\|}>\mathrm{k}_{\perp}$. In the present copper (II) complexes, $\mathrm{k}_{\|}$ $<\mathrm{k}_{\perp}$ indicating significant in-plane bonding. The values of $\alpha^{2}, \beta^{2}$ and $\gamma^{2}$ are consistent with strong in-plane $\sigma$ and in-plane $\pi$ bonding. The value (Table 1) of $\alpha^{2}$ and $\beta^{2}$, compared with other copper (II) complexes, are ionic in nature ${ }^{34}$.

\section{Electrochemical studies}


Electro activity of the complexes was studied in DMSO with $0.1 \mathrm{M} \mathrm{NaClO}_{4}$ as supporting electrolyte using cyclic voltammetry at a platinum working electrode. A representative voltammogram is shown in Fig. 3 and redox potential values are given in Table 2.The redox processes assigned as $\mathrm{Cu}$ (II) $\mathrm{Cu}(\mathrm{I})$ couples are irreversible. The valtammograms of the complexes consist of two well-separated peaks, one cathodic potential $\left(\mathrm{E}_{\mathrm{pc}}\right)$ and one anodic potential $\left(\mathrm{E}_{\mathrm{pa}}\right)$.In these complexes, reduction values were observed at more negative potential. The one electron stoichiometry of couple was confirmed by compression of the current with that of a known ${ }^{35}, \mathrm{Cu}^{\mathrm{I}}-\mathrm{Cu}^{\mathrm{II}}$ couple. The peak current ratio $\mathrm{I}_{\mathrm{pa}} / \mathrm{I}_{\mathrm{pc}}$ is less than unity, showing that the electron transfer reaction is followed by a chemical reaction (EC mechanism) ${ }^{36-38}$.

\section{Superoxide dismutase activity}

The SOD activities for the complexes were measured. Superoxide was enzymatically supplied from alkaline DMSO and SOD activity was evaluated by the NBT assay ${ }^{39}$ following the reduction of NBT to $\mathrm{MF}^{+}$ kinetically at $560 \mathrm{~nm}$. These complexes exhibit significant catalytic activity toward the dismutation of superoxide anions. The concentration causing $50 \%$ inhibition of NBT reduction is $\mathrm{IC}_{50}$. The SOD activity of complex 1 was shown in Fig.3. SOD values $\left(\mathrm{IC}_{50}\right)$ are in the range $45 \pm 5 \mu \mathrm{M}$. The observed $\mathrm{IC}_{50}$ values of the present copper (II) complexes are higher than the value exhibited by the native enzyme $\left(\mathrm{IC}_{50}=0.04 \mu \mathrm{mol} \mathrm{\textrm {dm } ^ { - 3 }}\right)$ on a molar base (note that the smaller the $\mathrm{IC}_{50}$ value, the higher the SOD activity). SOD values $\left(\mathrm{IC}_{50}\right)$ values of the present complexes are comparable to reported values ${ }^{40-42}$ for copper (II) (Table 2).The catalytic activity of $\mathrm{Ni}-\mathrm{SOD}$, however, is on the same high level as that of $\mathrm{Cu}-\mathrm{ZnSOD}$ at about $10^{9}\left(\mathrm{~mol} \mathrm{~L}^{-1}\right)^{-1} \mathrm{~S}^{-1}$ per metal center. SOD activities of copper (II) complexes are in the order $\mathbf{1}>\mathbf{3}>\mathbf{2}$. From this trend, it appears that inclusion of nitrogen donors reduces the SOD activity.

\section{Spectroscopic studies}

The electronic spectra of the complexes $\mathbf{1 - 3}$ were recorded in $100 \%$ DMSO solution at $25^{\circ} \mathrm{C}$. Complex 1 and 2 show a broad nonsymmetrical band with absorption maximum at $\sim 660 \mathrm{~nm}$ and at $\sim 400 \mathrm{~nm}\left(500 \mathrm{M}^{-1} \mathrm{~cm}^{-1}\right)$ assigned as LMCT (Fig 4). Such abservation ${ }^{43-45}$, are consistent with octahedral copper (II) complexes. The electronic spectrum of $\mathbf{3}$ in DMSO consists of a featureless band at 400nm, typical of a distorted octahedral chromophore $^{46,47}$. The complex also exhibits absorption at $300 \mathrm{~nm}$ assignable to LMCT transition ${ }^{48}$. All these values are far from that of aqueous $\mathrm{CuCl}_{2}$ at $820 \mathrm{~nm}$, indicating the complexes are not dissociated in solution. These complexes 1-3 exhibit the $v_{\mathrm{a}}(\mathrm{COO})$ and $v_{\mathrm{s}}(\mathrm{COO})$ at $1635-1665$ and $1300-1350 \mathrm{~cm}^{-1}$, respectively ${ }^{49}$. The bands in the rage $435-474 \mathrm{~cm}^{-1}$ which have been assigned to the $v(\mathrm{Cu}-\mathrm{N})$ bond ${ }^{50}$. Vibrations at $435-473 \mathrm{~cm}^{-1}$ (weak) (and expected below $400 \mathrm{~cm}^{-1}$; out of our measuring limit) can be attributed to $\mathrm{Cu}-\mathrm{O}$ and $\mathrm{Cu}-\mathrm{N}$ vibration $^{51,52}$

\section{Antimicrobial activity}

The antibacterial results, presented in Table 4 show clearly that all the newly synthesized copper (II) complexes possess good antimicrobial activity. The susceptibility of certain strains of bacteria towards the present metal complexes was judged by measuring the size of inhibition diameter the growth inhibitory effects were observed against the following bacterial pathogens E. coli and Streptococcus aureus. All of the compounds have significant antibacterial activity at $5 \times 10^{-4} \mathrm{gcm}^{-3}$ versus bacteria and fungi. Both antibacterial and antifungal activity were taken four concentration i.e. 5, 10, 15 and $20 \mathrm{mM}$ of each compound in DMSO. Certain strains of bacteria towards the present copper (II) complexes were determined by measuring the size of inhibition diameter. The antibacterial and antifungal activity of $[\mathrm{Cu}(\mathrm{HIda})(\mathrm{bipy})] \mathbf{1}$ is graphically presented in Fig.6 and 7. Both the bacteria are pathogens for humans, which causes dysentery and food poisoning, respectively. The area of zone of inhibition is less in the concentration of $5 \mathrm{mM}$ in both micro-organisms and more in $15 \mathrm{mM}$ concentration. This kind of observation is suggestive of that these complexes are effective against both pathogens. In case of complex 1 diameter of inhibition zone is highest for E.coli. It was noted that [Cu(HIda)(bipy)] 1 was more effective against E. coli than Streptococcus aureus and later showed somewhat resistant property against $[\mathrm{Cu}(\mathrm{HIda})(\mathrm{phen})] \mathbf{2}$ and $[\mathrm{Cu}(\mathrm{HIda})(\mathrm{dmp})] \mathbf{3}$. Among fungal species two isolates were taken into consideration and were Aspergillus and Penicillium sp. The zone of inhibition of these compounds against those fungi were recorded in Table 6.Similar trends were observed as in the case of bacteria. It was noted that Penicillium $s p$. was highly susceptible against $[\mathrm{Cu}(\mathrm{HIda})(\mathrm{bipy})]$ 1. Another fungi Aspergillus $s p$. Showed least effectiveness against [Cu(HIda)(phen)] 2 but comparatively more susceptible towards [Cu(HIda)(bipy)]1.In $[\mathrm{Cu}(\mathrm{HIda})(\mathrm{dmp})] \mathbf{3}$, the pattern of activity is complex and no clear trend can be ascertained. Such observations are comparable with other reported copper (II) complexes ${ }^{53-55}$.

\section{Conclusion}

[Cu(HIda)(bipy)] 1; [Cu(HIda)(phen) 2; [Cu(HIda)(dmp)] 3 were synthesized and characterized by using different physico-chemical techniques. The magnetic and spectroscopic data of all these complexes $\mathbf{1 - 3}$ indicate octahedral environment around $\mathrm{Cu}$ (II). SOD activities of reported complexes are in the order $\mathbf{1}>\mathbf{3}>\mathbf{2}$. Antibacterial and antifungal activities of the copper complexes have also been investigated. 


\section{Acknowledgements}

Our grateful thanks are due to the RSIC (SAIF), IIT Mumbai for EPR measurements, respectively. The Head RSIC (SAIF), Central Drug Research Institute, Lucknow is also thankfully acknowledged for providing analytical and spectral facilities. School of Environment Biology, A. P. S. University Rewa (M.P.), India for his help in antibacterial and antifungal screening. Financial assistance from U.G.C. Bhopal (F.No. MS-25/101030/0708/CRO), India is thankfully acknowledged.

\section{References:}

[1]. H. Sigel (Ed.), Metal ions in Biological System, vol.12, Marcel Dekker, New York (1981).

[2]. H. Sigel (Ed.), Metal ions in Biological Systems, Vol.13, Marcel Dekker, New York (1981).

[3]. T. Miura, A. Hori-i, H. Mototani and H. Takeuchi, Biochemistry, 38, 11560 (1999).

[4]. J. D. Ranford and P.J. Sadler, J. Chem. Soc., Dalton Trans., 3393 (1993).

[5]. G. Majella, S. Vivienne, M. Malachy, D. Michael and M. Vickie, Polyhedron, 18, 2931 (1999).

[6]. D. K. Saha, U. Sandbhor, K. Shirisha, S. Paddye, D. Deobagkar, C.E. Ansond and A. K. Powell, Bioorg. Med. Chem. Lett., 14, 3027 (2004).

[7]. M. A. Zoroddu, S. Zanetti, R. Pogni and R. Basosi, J. Inorg. Biochem., 63, 291 (1996)

[8]. R. N. Patel, N.singh, K. K. Shukla, V. L. N. Gundla and U. K. Chauhan, Spectrochim. Acta. A63, 21 (2006),

[9]. L. W. Oberley and G.R. Buettner Cancer Res, 39 (1979) 1141

[10]. J. M. Mc Cord, Biol. Med., 2, 307 (1986).

[11]. R N Patel, A. Singh, M. Choudhary, D. K. Patel, Juan N. Gutierrez and D. C. Lazarte, Transition Met Chem, 34,239(2009).

[12]. R. N. Patel, S. P. Rawat, M. Choudhary, V. P. Sondhiya, D. K. Patel, K. .K. Shukla, Y. Singh and R. Pandey, Inorg Chim Acta, 392, 283 (2012).

[13]. R. N. Patel, M. Choudhary, K. K. Shukla, N. Singh and A. Singh, J. Indian Chem. Soc., 88,789(2011).

[14]. G. Glugliarelli and S. Cannistrao, Nuove Cimento, 4D, 194 (1984).

[15]. R. G. Bhirud and T. S. Shrivastava, Inorg. Chim. Acta, 179, 125 (1991).

[16]. R. G. Bhirud and T. S. Shrivastava, Inorg. Chim. Acta, 179, 121 (1990).

[17]. D. Liu and K. Kwasniewka, Bull. Environ. Contam. Toxicol, 27, 289 (1981)

[18]. H.B. Gray and J. Ballhausen, J. Am. Chem. Soc., 85, 260 (1963).

[19]. V.P. Singh, A. Katiyar and S. Singh, J. Coord. Chem., 62, 1336 (2009).

[20]. I. Tabushi, Y. Taniguchi and H. Kato, Tetrahedron, 12, 1049 (1977).

[21]. W. J. Geary, Coord. Chem. Rev., 7, 81 (1971).

[22]. A. Valent, M. Kotitutova, O. Svajlennova, D. Hudecova, P. Olejnikova, and M. Melknik, J. Coord. Chem., 57, 1279 (2004).

[23]. R. N. Patel, N. Singh and V. L. N. Gundla, Polyhedron, 26,757 (2007).

[24]. R. N. Patel, K. K. Shukla, A. Singh, M. Choudhry, U.K. Chauhan and S. Dwivedi, Inorg. Chim. Acta, 362, 4891 (2009).

[25]. G. Wilkinson, R.G. Gillard and J.A. Mc Cleverty, Comprehensive Coordination Chemistry, 5, 674 (1987).

[26]. A. W. Addision, In Copper Coordination Chemistry: Biochemical and Inorganic Perspectives, K. D. Karlin, J. Zubieta (Eds), Adenine, Guilderland, New York, 109 (1983).

[27]. A. M Thomas, A.D. Naik, M. Nethaji and A. R. Chakravorty, Indian J. Chem., 43A, 691 (2004).

[28]. R. N. Patel, Inorg. Chem. Acta, 363, 3838(2010).

[29]. P. F. Rapheat, E. Manoj and M. R. P. Kurup, Polyhedron, 26, 818 (2007)

[30]. U. weser, L. M. Schubotz and E. Lengfetder, J. Mol. Cat., 13, 249 (1981).

[31]. J. L. Pierre, P. Chautemps, S. Refaif, C. Beguim, A. E. Marzouki, G. Serratrice, E. Saint - Aman and P. Ray, J. Am. Chem. Soc., 117, 1965 (1995).

[32]. G. F. Bryce, J. Phys. Chem., 70, 3549 (1966).

[33]. R. N. Patel, N. Singh, K. K. Shukla, V. L. N. Gundla and U. K. Chauhan, Spectrochim Acta, A63, 21 (2006)

[34]. B. G. Malmstrom and T. Vanngard, J. Mol. Biol., 2, 118 (1960).

[35]. J. Dindo, V. Roy, G. Mostafa, T. H. Li, A-Usman, I. A. Razak, S. Chantrapromma, H. K. Fun and C. Sinha, Polyhedron, 22, 247 (2003).

[36]. D. H. Evans, Chem. Rev., 90, 739 (1990).

[37]. S. Parveen and F. Arjmand, Indian, J. Chem. Soc., 44A, 1151 (2005).

[38]. R.N. Patel, V.L.N. Gundla and D.K. Patel, Indian J. Chem., 47A, 353 (2008).

[39]. J. Han, Y. Xing, C. Wang. P. Hou, F. Bai, X. Zeng, X. Zhang and M. Ge., J. Coord. Chem., 62, 745 (2009).

[40]. R. N. Patel, K. K. Shukla, Anurag Singh, M. Choudhary and D. K. Patel, J. Coord. Chem., 63, 586 (2010)

[41]. R. N. Patel, N. Singh and V. L. N. Gundla. Polyhedron, 25, 3312 (2006)

[42]. H.D. Youn, E.J. Kim, J.H. Roe., Y.C. Hah and S.O. Kang, J. Biochem., 318, 889 (1996).

[43]. A. B. P. Lever, Inorganic Electronic Spectroscopy (Elsevier. Amsterdam) (1968).

[44]. G. Wilkinson, R. G. Gillard and J.A. McCleverty, Comprehensive Coordination Chemistry, 5, 674 (1994).

[45]. A. Pramanik, S. Abbina and G. Das, Polyhedron, 26, 5225 (2007).

[46]. $\quad$ A.B.P. Lever, Inorganic Electronic Spectrascopy, $2^{\text {nd }}$ Edn, P. 554, Elsevier, Amstrerdam (1984).

[47]. R. N. Patel, K. K. Shukla, A. Singh, D. K. Patel and V. P. Sondhiya, J. Coord. Chem., 64, 902(2011)

[48]. D. Harrison and B.J. Hathaway, Acta Crystallography. Sect. B, 35, 2910 (1979).

[49]. K. Nakamoto, P. McCarthy and B. Miniatus, Spectrochim Acta., 21, 379 (1965)

[50]. D. X. West and N. M. Kudzu, Transition Met. Chem., 21, 52 (1996).

[51]. K. Nakamoto, Infrared and Raman Spectra of Inorganic and Coordination Compounds, $5^{\text {th }}$ edn (Wiley, New York) (1997).

[52]. M. Boca, M.Izakuvic, G. Kickelbick, M-Valko, F. Renz, H. Fuess and K. Matuzsna, Polyhedron, 24, 1913 (2005).

[53]. M.T.H. Tarafder, K.B. Chew. K.A. Crouse, A.M. Ali, B.M. Yamin and H. K. Fun, Polyhedron, 21, 2683(2002).

[54]. R. Nagar, J. Inorg. Biochem. 40, 349(1990).

[55]. R. K. Jain and A. P. Mishra, J. Serbian Chem. Soc.,77,1013(2012). 
Table 1 EPR spectral parameters of the copper (II) complexes.

\begin{tabular}{lccc}
\hline EPR Parameters & {$[\mathrm{Cu}(\mathrm{HIda})(\mathrm{bipy})] \mathbf{1}$} & {$[\mathrm{Cu}(\mathrm{HIda})(\mathrm{phen})] \mathbf{2}$} & {$[\mathrm{Cu}(\mathrm{HIda})(\mathrm{dmp})] \mathbf{3}$} \\
\hline Polycrystalline state $(298 \mathrm{~K})$ & 2.215 & 2.1696 & 2.110 \\
$\mathrm{~g}_{\|}$ & 2.087 & 2.0862 & 2.048 \\
$\mathrm{G}_{\perp}$ & 2.151 & 2.127 & 2.079 \\
$\mathrm{~g}_{\text {iso }}$ or $\mathrm{g}_{\mathrm{av}}$ & & & \\
$\mathrm{DMSO}(77 \mathrm{~K})$ & 2.285 & 2.2065 & 2.233 \\
$\mathrm{~g}_{\|}$ & 2.058 & 2.0404 & 2.069 \\
$\mathrm{~g}_{\perp}$ & 160 & 155 & 145 \\
$\mathrm{~A}_{\| I}(\mathrm{G})$ & 2.51 & 3.80 & 2.98 \\
$G$ & 0.790 & 0.661 & 0.676 \\
$\alpha^{2}$ & 0.939 & 0.997 & 1.044 \\
$\beta^{2}$ & 0.834 & 0.862 & 1.123 \\
$\gamma^{2}$ & 0.776 & 0.658 & 0.758 \\
$\mathrm{k}_{\|}$ & 0.689 & 0.569 & 0.705 \\
$\mathrm{k}_{\perp}$ & 142 & 152 & 165 \\
$f\left(\mathrm{~cm}^{-1}\right)$ & & & \\
\hline
\end{tabular}

Table 2 Cyclic voltametric measurements of copper (II) complexes.

\begin{tabular}{|c|c|c|c|c|c|c|c|c|}
\hline $\begin{array}{l}\text { Complexes with } \\
(\mathrm{mV} / \mathrm{s})\end{array}$ & Scan rate & $\begin{array}{l}\mathrm{E}_{\mathrm{pc}} \\
(\mathrm{mV})\end{array}$ & $\mathrm{I}_{\mathrm{pc}}(\mu \mathrm{A})$ & $\mathrm{E}_{\mathrm{pa}}(\mathrm{mV})$ & $\mathrm{I}_{\mathrm{pa}}(\mu \mathrm{A})$ & $\begin{array}{c}\Delta \mathrm{E}_{\mathrm{p}} \\
(\mathrm{mV})\end{array}$ & $\mathrm{E}^{\prime}{ }_{0}(\mathrm{mV})$ & $\mathrm{I}_{\mathrm{pa}} / \mathrm{I}_{\mathrm{pc}}(\mu \mathrm{A})$ \\
\hline$[\mathrm{Cu}(\mathrm{HIda})($ bipy)$]$ & $\mathbf{1}$ & & & & & & & \\
\hline 100 & & -590 & 1.9823 & -260 & 1.0356 & 330 & 425 & 0.522 \\
\hline 200 & & -546 & 2.6754 & -290 & 2.2248 & 256 & 418 & 0.831 \\
\hline$[\mathrm{Cu}(\mathrm{HIda})($ phen $)]$ & 2 & & & & & & & \\
\hline 100 & & -565 & 1.8723 & -360 & 1.4256 & 205 & 462 & 0.761 \\
\hline 200 & & -520 & 2.2352 & -385 & 2.0219 & 135 & 452 & 0.904 \\
\hline$[\mathrm{Cu}(\mathrm{HIda})(\mathrm{dmp})]$ & 3 & & & & & & & \\
\hline 100 & & -585 & 1.4523 & -250 & 1.3215 & 335 & 417 & 0.909 \\
\hline 200 & & -552 & 2.8769 & -290 & 2.5460 & 262 & 421 & 0.884 \\
\hline
\end{tabular}

$\Delta \mathrm{E}_{\mathrm{p}}=\mathrm{E}_{\mathrm{pa}}-\mathrm{E}_{\mathrm{pc}} \mathrm{E}^{\mathrm{o}}=\left(\mathrm{E}_{\mathrm{pa}}+\mathrm{E}_{\mathrm{pc}}\right) / 2$

Table 3 Superoxide dismutase activity of some copper (II) complexes.

\begin{tabular}{|c|c|c|c|}
\hline S.N. & Complexes & $\mathrm{IC}_{50}\left(\mu \mathrm{mol} \mathrm{dm}^{-3}\right)$ & Reference \\
\hline 1. & {$\left[\mathrm{Cu}(\mathrm{II})(\text { aspirinate })_{2}(\mathrm{DMSO})_{2}\right]$} & $>400$ & 35 \\
\hline 2. & {$\left[\mathrm{Cu}(\mathrm{II})(\text { aspirinate })_{2}(\operatorname{ImH})_{2}\right]$} & 160 & 35 \\
\hline 3. & {$\left[\mathrm{Cu}(\mathrm{II})(\text { aspirinate })_{2}(4-\mathrm{pic})_{2}\right]$} & 100 & 35 \\
\hline 4. & SOD & 0.04 & 35 \\
\hline 5. & {$\left[\mathrm{Cu}(\mathrm{SAA})\left(\mathrm{H}_{2} \mathrm{O}\right)\right]$} & 63 & 36 \\
\hline 6. & {$[\mathrm{Cu}(\mathrm{SAA})(\mathrm{MeImH})]$} & 35 & 36 \\
\hline 7. & {$[\mathrm{Cu}(\mathrm{SAA})(\mathrm{Et} \operatorname{ImH})]$} & 43 & 36 \\
\hline 8. & {$[\mathrm{Cu}(\mathrm{SAA})(\operatorname{ImH})]$} & 30 & 38 \\
\hline 9. & {$[\mathrm{Cu}(\mathrm{SAA})($ bipy)$]$} & 56 & 38 \\
\hline 10. & {$[\mathrm{Cu}(\mathrm{SAA})(\mathrm{phen})]$} & 50 & 38 \\
\hline 11. & {$[\mathrm{Cu}($ HIda)(bipy)] $\mathbf{1}$} & 50 & This work \\
\hline 12. & {$[\mathrm{Cu}(\mathrm{HIda})($ phen $)] \quad \mathbf{2}$} & 40 & This work \\
\hline 13. & {$[\mathrm{Cu}(\mathrm{HIda})(\mathrm{dmp})] \quad \mathbf{3}$} & 49 & This work \\
\hline
\end{tabular}

Table 4 Antibacterial activity of copper (II) complexes.

\begin{tabular}{|c|c|c|}
\hline \multirow[t]{2}{*}{ Complexes (mM) } & \multicolumn{2}{|c|}{ Diameter of inhibition zone (in mm) } \\
\hline & S. aureus & E.col \\
\hline \multicolumn{3}{|l|}{$[\mathrm{Cu}$ (HIda)(bipy)] $\mathbf{1}$} \\
\hline 5 & 8 & 10 \\
\hline 10 & 12 & 13 \\
\hline 15 & 14 & 18 \\
\hline 20 & 18 & 30 \\
\hline \multicolumn{3}{|l|}{$[\mathrm{Cu}(\mathrm{HIda})($ phen $)] \mathbf{2}$} \\
\hline 5 & 6 & 9 \\
\hline 10 & 11 & 12 \\
\hline 15 & 12 & 14 \\
\hline 20 & 16 & 22 \\
\hline
\end{tabular}


Table 5 Antifungal activity of copper (II) complexes.

\begin{tabular}{|c|c|c|}
\hline \multirow[t]{2}{*}{ Complexes (mM) } & \multicolumn{2}{|c|}{$\%$ Inhibition of spore germination } \\
\hline & A.sp.(mg mL $\left.\mathrm{mL}^{-1}\right)$ & P. sp.(mg mL $\left.\mathrm{mL}^{-1}\right)$ \\
\hline \multicolumn{3}{|l|}{$[\mathrm{Cu}(\mathrm{HIda})$ (bipy) $] \mathbf{1}$} \\
\hline 5 & 8 & 10 \\
\hline 10 & 12 & 14 \\
\hline 15 & 16 & 18 \\
\hline 20 & 24 & 26 \\
\hline \multicolumn{3}{|l|}{$[\mathrm{Cu}(\mathrm{HIda})($ phen $)] 2$} \\
\hline 5 & 10 & 12 \\
\hline 10 & 14 & 16 \\
\hline 15 & 18 & 18 \\
\hline 20 & 26 & 27 \\
\hline
\end{tabular}

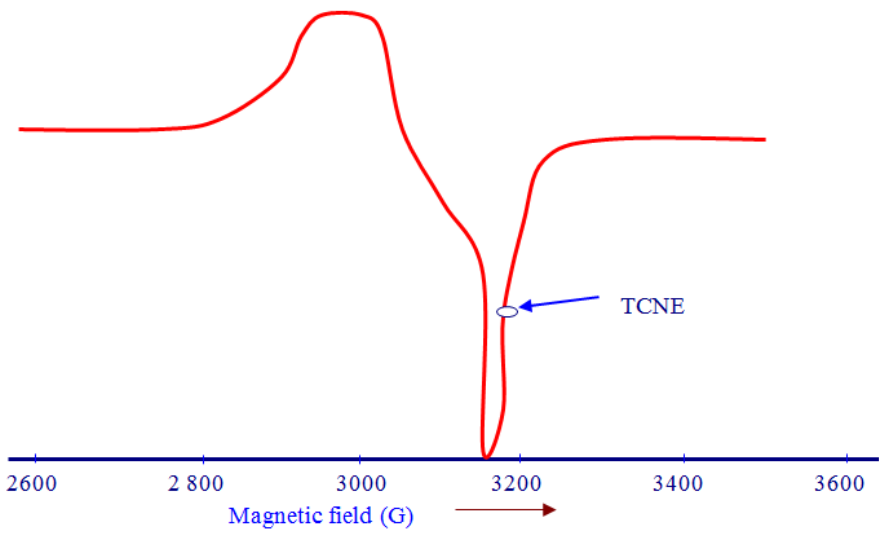

Fig. 1 EPR Spectrum (L.N.T.) in 100\% DMSO of the Complex [Cu(HIda) bipy)] 1
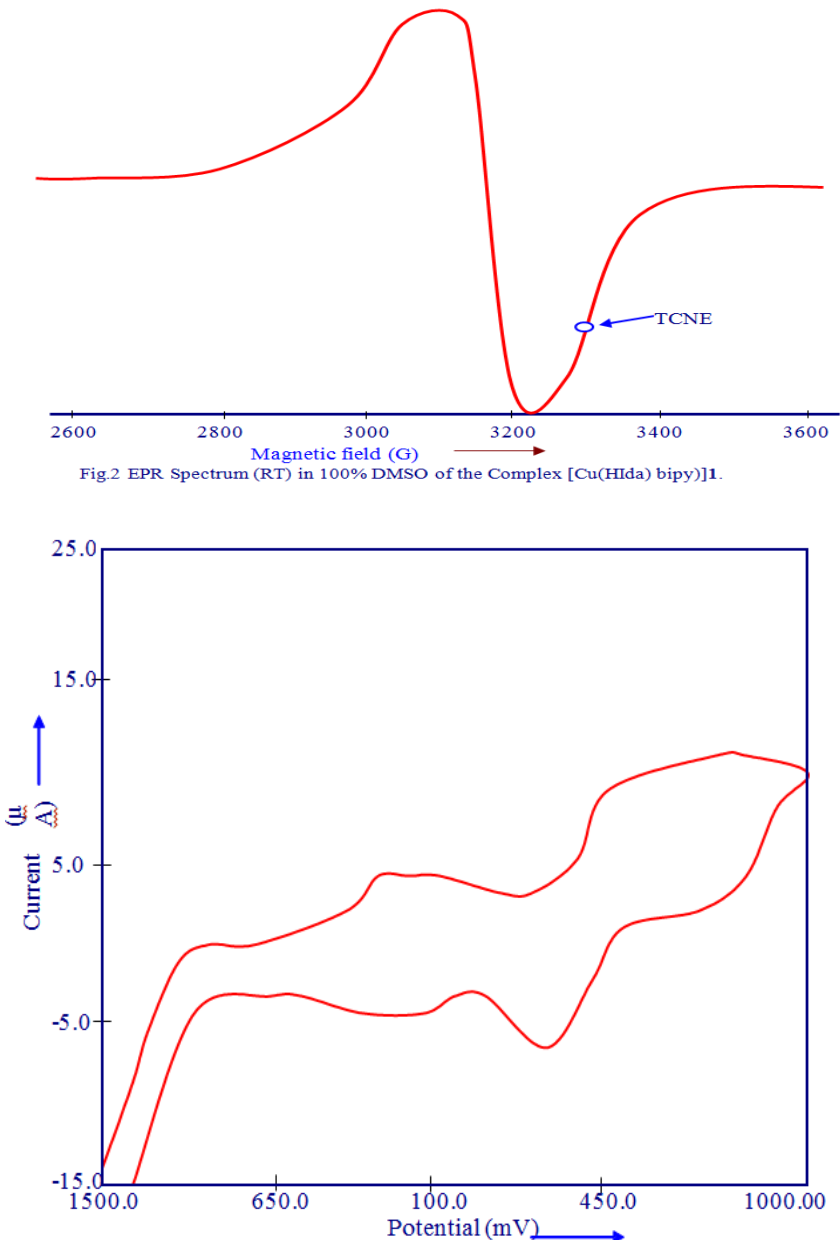

Fig. 3 Cyclic voltammogram $\left(3 \times 10^{-3} \mathrm{M}\right)$ of complex $[\mathrm{Cu}(\mathrm{HIda})$ bipy $\left.)\right] \mathbf{1}$ 


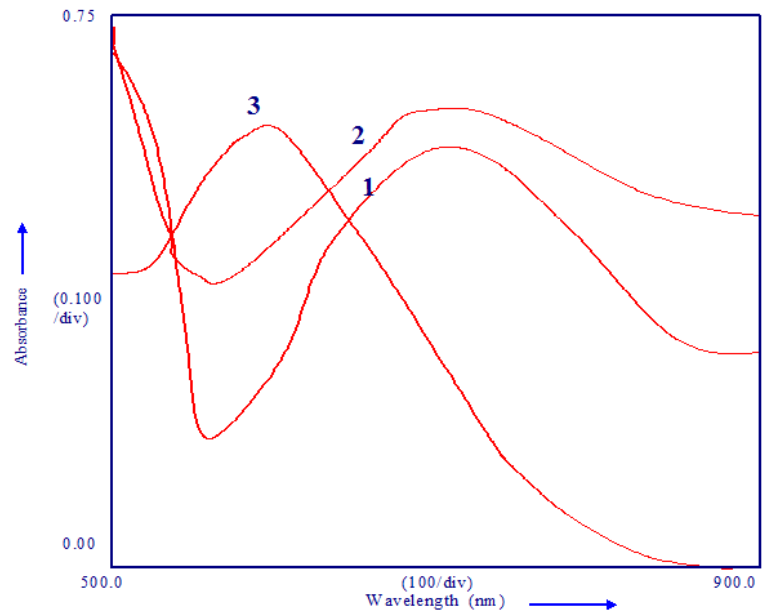

Fig. 4 The UV-Vis spectra $\left(3 \times 10^{-3} \mathrm{M}\right)$ of complexes 1-3.

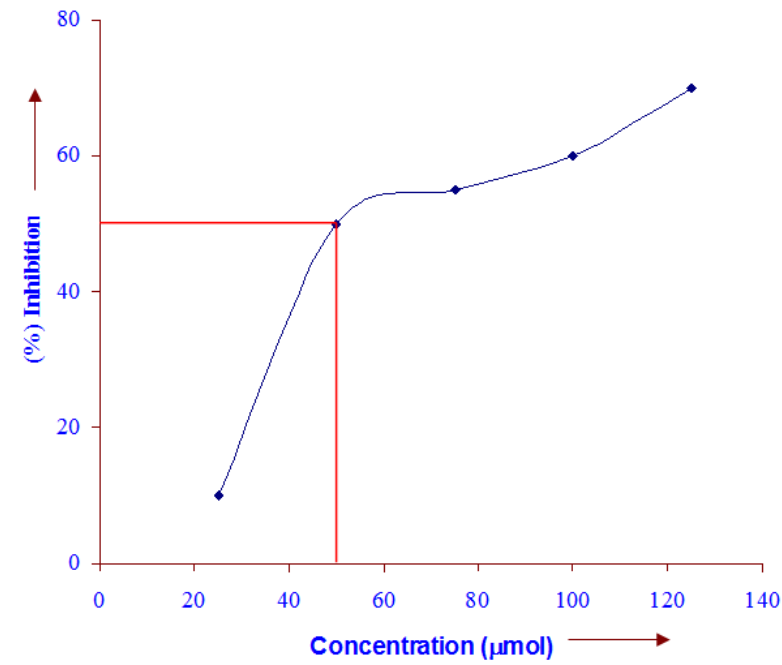

Fig. 5 Superoxide dismutase activity of $[\mathrm{Cu}(\mathrm{HIda})(\mathrm{bipy})] 1$

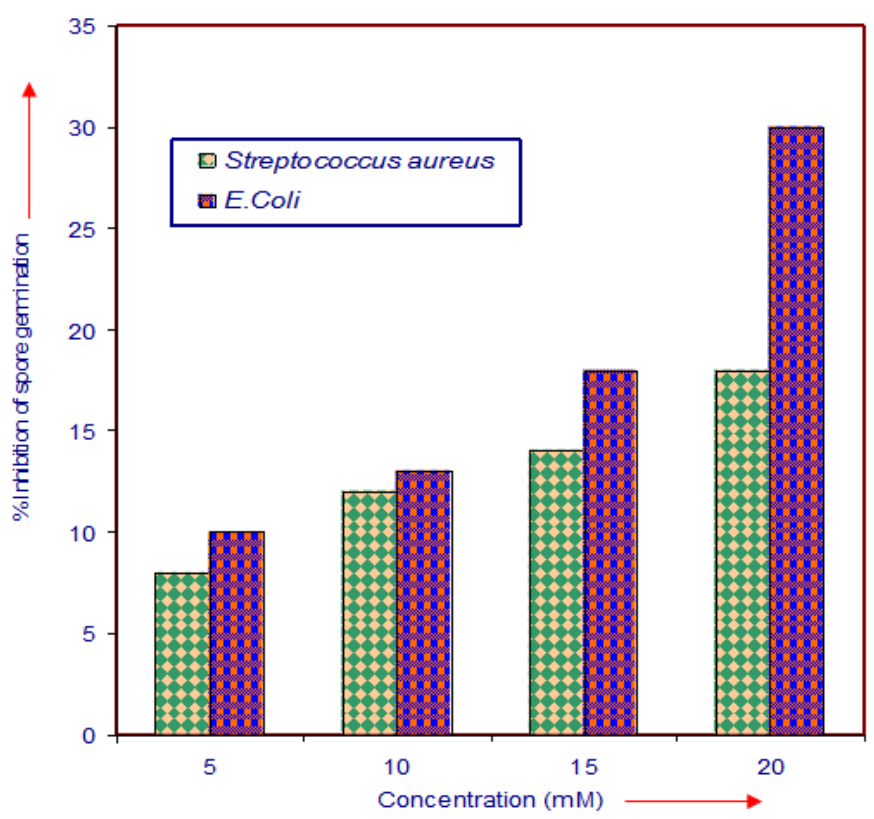

Fig. 6 Antibacterial activity of $[\mathrm{Cu}(\mathrm{HIda})($ bipy) $] \mathbf{1}$ 


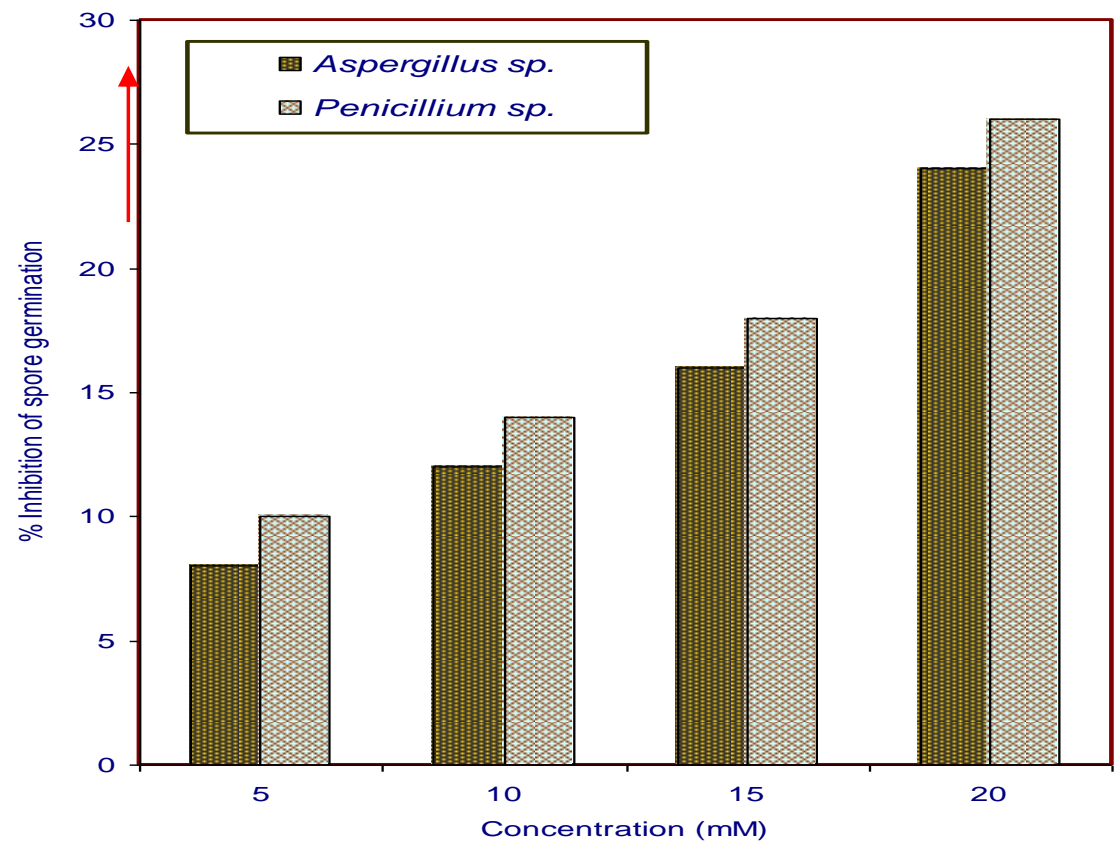

Fig. 7Antifungal activity of [Cu(HIda)(bipy)] 1 